\title{
Evaluation of Corporate Governance Influence on Internal Control System: a Case Study of Selected Banks in South Western, Nigeria
}

\author{
Ade deji D. B. \\ Department of Accountancy, Rufus Giwa Polytechnic, Owo, Nigeria
}

\begin{abstract}
This paper critically evaluates the influence of corporate governance on internal control systems of banks in South Western Nigeria. The objective of the paper is to evaluate the effect of corporate governance on internal control system in relation to ineffectiveness, distresses and failures in banking organisations. It focuses on promoting effectiveness in the banking industry through the adoption of various variables towards achieving set goals and stakeholders' welfare in banks. Since co mpanies are the entities that create economic value, the place of corporate governance in pro moting effective internal control that will aid economic efficiency, transparency and accountability within an organization cannot be underrated most especially in the banking industry of developing economies. A well-structured questionnaire pre-coded and designed in English language.was administered and used to collect data from 61 respondents who were managers, accountants, adminis trative officers and marketers in some selected banks in South-West, Nigeria. Data for the research were analysed and tested using Mean score analyses and Pearson moment correlation. Findings reveal that that failures and distresses in the banking industry were as a result of weaknesses in manage ment governance activities and control. The paper concludes that the board of governance of banks has so much responsibility in ensuring effective internal control system and recommendations were suggested as to adequate monitoring and effective supervision to ensure compliance and receiving adequate feedback from the management for effective control.
\end{abstract}

Keywords Corporate Governance, Distress, Ineffectiveness, Internal Control

\section{Introduction}

Corporate governance can be described as the government of corporation, entity or an organisation. It is the set of processes, customs, policies, laws and institutions affecting the way a corporation or company is directed, administered or controlled[1]. The role of corporate governance in reshaping the system of internal control in an organisation cannot be under-estimated as control is one of the main arms of corporate governance. Since companies are the entities that create economic value, the place of corporate governance in promoting econo mic efficiency, transparency and accountability with in an organisation cannot be underrated most especially in the banking industry considering the es sential ro les that banks play in the financial systems of developing economies and the widespread banking reforms that these economies have implemented.

Internal control has been described as the systematic measures instituted by an organisation to conduct its

* Corresponding author:

dbadedeji@gmail.com (Adedeji D. B.)

Published online at http://journal.sapub.org/mm

Copyright (C) 2012 Scientific \& Academic Publishing. All Rights Reserved business in an orderly and efficient manner, safeguard its ass ets and resources, deter and detect errors, fraud and theft, ensure accuracy and completeness of its accounting data, produce reliable and timely financial and management information, and ensure adherence to its policies and plans [2](free dictionary, 2010).

Before the advent of the code of best practise on corporate governance, establishment of a sound system of internal control by management has been the major means of achieving the company's goals and objectives. Where you have a sound system of internal control system the organisation is most likely to achieve its goals and objectives but this has not been realisable in the banking industry, where a severe banking crisis has been the experience in most Nigeria banks.

A banking crisis occurs when there is systemic crisis, that is, a fairly reasonable proportion of banks in the system are unable to meet their obligations to customers, owners and the economy as a result of weaknesses in their financial, operational and managerial conditions, which rendered them either illiquid and /or insolvent. Alashi[3](2002) states that bank cris is becomes severe when a bank shows most or all of the following conditions: gross under-capitalization in relation to the level and character of business; a high level of 
non-performing loans to total loans; illiquidity as reflected in banks inability to meet customers' cash withdrawals and/ or a persistent overdrawn position with the Central Bank; weak management as reflected by poor as set quality; insider abuse; inadequate internal controls and fraud among others. This has been the condition in most Nigeria banks.

Accordingly, Alawiye[4] opined that the Nigeria banking system has suffered very significant setbacks and acute systemic deterioration which resulted in the distress syndrome that caused a near total collapse of the public confidence in the system. Between 1990 and 2004 mo re than 50 percent of the institutions comprising 130 commercial banks and 68 merchant banks were suspected to be plagued by the distress cankerworm. This bad situation was warranted by directors and the senior management staff of banks disregard for standard procedures and deliberate breaking of operating rules. The summary of the problem with the banking system is lack of corporate governance that has resulted in total deterioration in the management system of the banking industry.

Recent crisis in the banking industry confirms other outrageous practices of managing directors whereby the managing directors of eight banks were removed and replaced[5]. Importantly, the quality of management can make a very big difference to the health of a bank, hence, the role of good corporate governance in promoting effective internal control system that will reduce ineffectiveness and distress in the banking industry.

Similarly, the Central Bank of Nigeria (CBN)[6] identifies some of these prevalent problems in the banking industry to include ineffective board oversight functions; fraudulent and self-serving practices among members of the board, and management staff; weak internal control and non-complianc e with ru les and laws guiding banking business. The situation in the governance of banks was so bad that the 'Soludo agenda' prescribed as part of its proactive measures, the enforcement of the principle of corporate governance in the new post-consolidated banking system, and there was a radical embrace of the principles of good governance by every surviving bank.

Thus, the overall aim of this study is to evaluate the impact of corporate governance in promoting effective internal controlsystem that will reduce ineffectiveness and distress in the banking industry. It will be of great importance to future promoters, companies and shareholders as it will serve as a sure foundation for the bas is of operation. Moreover, it will help managements and directors of companies to cultivate and value the culture of promoting effective internal control system in organisations.

\section{Literature Review}

\subsection{Concept of Cor porate Governance and Internal Control}

Many authors have written different studies on corporate governance, but there has not been a write up covering the aspect of internal control. Anya[7] on corporate governance as an effective tool for combating financial and economic crimes in public sector dwelt so much on the public sector rather than corporate organisations. Nasser[8], on corporate governance in Islam banks, revealed that governance structures in Islamic banks are quite different from conventional banks, The study fails to reveal how these principles of Islamic banking can be applied in non-Is lamic community. A run and Turner[9] on corporate governance of banks in developing economics concepts and issues, discus ses the corporate governance of banking institutions in developing economies and considered the essential roles that banks play in financialsystems of developing econo mies and the widespread banking reforms that these economies have implemented, The study failed to recognize the important roles of the regulatory authorities in promoting good corporate governance system especially in banking industry. Alawiye[4] on corporate governance and banking reforms agenda and imperative for corporate governance in a consolidated banking environment identified the various problems plaguing the banking industry in Nigeria as lack of corporate governance, and the embracement of the reform agenda principle of corporate governance but it fails to recognise how the principle of corporate governance can be used to improve on the existing system of internal control.

Organisation of Economic Co-operation and Development (OECD) (2004)[10] defines corporate governance as the system by which business corporations are directed and controlled. Akintola[11] defines corporate governance as how institutions are directed, controlled and made accountable so that they can fulfil their mandate to the stakeholders and the society at large in a sustainable manner. Donovan[12] defines corporate governance as an internal system encompassing policies, processes and people, which serve the needs of shareholders and other stakeholders by directing and controlling management activities with good business savvy, objectivity, accountability and integrity. Sound governance is reliant on external market place commitment and legislation, plus a healthy board culture which safeguards policies and processes. It is the effective procedure by which corporations are directed and controlled. Fakunle[13] opines that the need for corporate governance has evolved as business evolved simply because stakeholder especially the shareholders are always separated from the management and control of the entities in which they have invested. The import of corporate governance to the whole economy cannot be under-estimated; it is a system that has been design to perfect that which is lacking in all sectors of life both in the public and private sectors. Alawiye[4] postulates that practicing the principles of governance enables a corporate entity to operate within the bounds of responsibility; transparency, accountability and decorum, and that reduce the need for statutory regulations. Management will voluntarily develop the culture of compliance which will foster sound management and reduce the incidence of crisis. There is a need therefore to continually raise the awareness of the Nigeria private sector 
especially the banking industry in the area of corporate governance[14].

Institute of Chartered Accountants (ICAN)[15] opines that internal control includes all the policies and procedures adopted by the directors and management of an entity to assist in achieving their objectives of ensuring as far as practicable the orderly and efficient conduct of its business including adherence to internal policies, the safeguarding of assets, the prevention and detection of fraud and error, the accuracy and completeness of the accounting records and timely preparation of reliable financial information. Two elements were identified from the definition above, which are control procedures and control environment. Control environment means the overall attitude, awareness and actions of directors and managements regarding internal controls and their importance in the entity. It encompasses the management style, corporate culture and values shared by all emp loyees. Control procedures' are those policies and procedures in addition to the control environ ment which are established to achieve the entity's specific objectives. They include in particular procedures designed to prevent or to detect and correct errors

\subsection{Internal Control Requirements of the Combined Code}

The Combined Code of the Turnbull Committee on Corporate Governance (2003) was published to:

1. Provide guidance to assist listed companies to implement the requirements in the Code relating to internal control;

2. Make the board maintain a sound system of internal control to safeguard shareholders' investment and the company's assets;

3. Mandate the directors, at least annually, conduct a review of the effectiveness of the group's system of internal control and should report to shareholders that they have done so. The review should cover all controls, including financial, operational and compliance controls and risk management.

Companies which do not have an internal audit function should from time to time review the need for one. Organisation of Economic Co-operation and Development (OECD)[10] defines corporate governance as the system by which business corporations are directed and controlled.

\subsection{Maintaining a Sound System of Inter nal Control}

To maintain a sound system of internal control as highlighted by the combined code (2003), all the stakeholders within the organisation have one responsibility or the other to perform:

i. The board of directors is responsible for the company's system of internal control.

It should set appropriate policies on internal control and seek regular as surance that will enable it to satis fy it that the system is functioning effectively.

ii. The board must further ensure that the system of internal control is effective in managing risks in the manner which it has approved.

Also, in determining its policies with regard to internal control, and thereby assessing what constitutes a sound system of internal control in the particular circumstances of the company, the board's deliberations should include consideration of the following factors:

i. the nature and extent of the risks facing the company;

ii. The extent and categories of risk which it regards as acceptable for the company to bear;

iii. The like lihood of the risks concerned materialising;

iv. Company's ability to reduce the incidence and impact on the business of risks that do materialise; and

$\mathrm{V}$. the costs of operating particular controls relative to the benefit thereby obtained in managing the related risks.

Moreover, it is the role of management to implement board policies on risk and control. In fulfilling its responsibilities, management should identify and evaluate the risks faced by the company for consideration by the board and design, operate and monitor a suitable system of internal control which implements the policies adopted by the board. All employees have some responsibility for internal control as part of their accountability for achieving objectives. They, collectively, should have the necessary knowledge, skills, information and authority to establish, operate and monitor the system of internal control. This will require an understanding of the company, its objectives, the industries and markets in which it operates, and the risks it faces

Also reviewing the effectiveness of internal control is an essential part of the board's responsibilities. The board will need to form its own view on effectiveness after due and careful enquiry based on the information and assurances provided to it. Management is accountable to the board for monitoring the system of internal control and for providing assurance to the board that it has done so.

\section{Data and Methodology}

The data presented in this paper were obtained from research conducted by the author on corporate governance in selected banks in Southwest Nigeria. To achieve the specific objective of the research, survey research design was used. Independent variable is Corporate Governance and dependent variables are Internal Control, Ineffectiveness and Distress. Population consist of all 24 functional banks in Nigeria. Five (5) banks that a mounted to $20.3 \%$ of the twenty four functional banks located in southwest Nigeria were purposively sampled. The sampled banks were United Bank for Africa (UBA), First Bank of Nigeria Plc (FBN), Skye Bank, Eco Bank and Guarantee Trust Bank (GTB) which comprises of two (2) first generation banks and three (3) new generation banks. The research instrument used was a well structured questionnaire prepared by the researcher and administered with the assistance of research assistants. The Mean Score method was used to analyse data obtained from res earch question, Pears on Product Coeffic ient of corre lation 
was used to test the hypothesis.

\section{Empirical Results and Discussion}

In this section, data for this study were analysed and presented based on the research questions and hypotheses that guided the study.

\subsection{Analysis of Selected Surveyed B anks}

Responses from the five selected banks were analysed in Table 1 below.

Table 1. Analysis of Surveyed Banks

\begin{tabular}{cccc}
\hline S/N & Banks & $\begin{array}{c}\text { Frequenc } \\
\text { y }\end{array}$ & $\%$ \\
\hline 1 & GTB & 12 & 20 \\
2 & UBA & 7 & 13 \\
3 & SKYE & 9 & 15 \\
4 & ECO & 16 & 27 \\
5 & FBN & 15 & 25 \\
\hline & Total & 59 & 100 \\
\hline
\end{tabular}

From Table 1 above, five major banks were examined, the frequencies and the percentage of their responses were analysed, with Eco bank having the highest response of $27 \%$, followed with FBN, with $25 \%$.

\subsection{Analyses of Research Questions / Tests of Hypotheses}

Research question; How can we say categorically that the directors and management activities influence ineffectivene ss, distress and failures in banking organisation?

Weaknesses of internal control system by Directors and Management in relation to distresses and failures were investigated and analysed based on the responses from the survey. Table 2 shows the result of Means scores on weaknesses in internal control in relation to distresses and failures.

Table 2. Mean scores (MS) and Ranks for Responses on Weaknesses in Internal Control in Relation to Distresses and Failures

\begin{tabular}{|c|c|c|c|c|c|c|c|c|c|c|}
\hline No & $\mathrm{X}$ & $\mathrm{SA}$ & $\mathrm{A}$ & $\mathrm{N}$ & $\mathrm{D}$ & $\mathrm{SD}$ & $\sum \mathrm{F}$ & $\sum \mathrm{FX}$ & $\mathrm{X}$ & RANK \\
\hline 1 & $\mathrm{~F}$ & 11 & 36 & 3 & 8 & 5 & 61 & 229 & 3.75 & 3 \\
\hline 2 & $\mathrm{~F}$ & 10 & 43 & 2 & 8 & 1 & 61 & 245 & 4.02 & 1 \\
\hline 3 & $\mathrm{~F}$ & 2 & 12 & 10 & 28 & 10 & 61 & 154 & 2.52 & 5 \\
\hline 4 & $\mathrm{~F}$ & 2 & 10 & - & 33 & 17 & 61 & 133 & 2.18 & 6 \\
\hline 5 & $\mathrm{~F}$ & 1 & 6 & 2 & 33 & 18 & 61 & 119 & 3.05 & 7 \\
\hline 6 & $\mathrm{~F}$ & 3 & 17 & 14 & 17 & 10 & 61 & 169 & 2.77 & 4 \\
\hline 7 & $\mathrm{~F}$ & 22 & 21 & 9 & 5 & 2 & 61 & 233 & 3.82 & 2 \\
\hline
\end{tabular}

Note: Note:

$\mathrm{SA}=$ Strongly Agree

$\mathrm{A}=$ Agree; $\mathrm{U}=$ Undecided'; $\mathrm{D}=$ Disagree; $\mathrm{SD}=$ Strongly Disagree; $\mathrm{X}=5$ or 4 or 3 or 2 or $1 ; \sum \mathrm{F}=$ Summation of Frequency

\section{Hypothesis;}

$\mathrm{H}_{\mathrm{o}}$ : Directors and management of banks were not significantly responsible for the weaknesses in the internal control system and general ineffectiveness, distresses and failures.

The above hypothesis was tested using Pearson Product moment of Correlation analysis as shown in Table 3 below:

Table 3. Pearson Correlation Analysis on Hypothesis

\begin{tabular}{|c|c|c|}
\hline & Section B2 1 & B2 7 \\
\hline Section B2 1 Pearson Correlation & 1 & $.87 * *$ \\
Sig. (2- tailed) & & .000 \\
$\mathrm{~N}$ & 59 & 59 \\
\hline Section B2 7 Pearson Correlation & $.87^{* *}$ & 1 \\
Sig. (2- tailed) & .000 & \\
$\mathrm{~N}$ & 59 & 59 \\
\hline
\end{tabular}

**. Correlation is significant at 0.01 level (2-tailed).

Where:

B2 1 = Ineffectiveness in operation resulting from weaknesses in the system of internal control

B2 $7=$ Distresses and failu res experienced in the past as a result of poor governance by management

The value of Pearson Correlation Coefficient (R) is .87 (Table 3). The result in the table revealed that there was a significantly positive relationship between Section B2 1 and B2 7.

\subsection{Summary of Findings}

It was observed from the result of Table 2 that items 1 and 2 have the highest values $X$ of 3.75 and 4.02 respectively revealing from the respondents that ineffectiveness in operation was as a result of weaknesses in internal control system. Also, in item 3 it can be inferred from the responses that management do override the internal control systems. Besides, item 7 with the mean core of 3.82 a ffirms that the distresses and failures in time past was due to weaknesses in directors and management governance activities. This supports the view of Alawiye[4] that failures and distresses in the banking industry in time past were as a result of weaknesses in management governance activities and control. From the responses, adequate systems of internal control have been put in place in the various banks, but there is the need for adequate compliance to back it up. From the tested hypothesis, in Table 3 the correlation coefficient $\mathrm{R}$ is .84 , which signifies that that there was a significantly positive relationship between Section B2 1 and B2 7 . Therefore, the alternative assumption that weaknesses in director and management internal control activities significantly influence general distresses and failures in banks is true.

\section{Conclusions and Recommendations}

This paper carefully reviews the system of corporate governance and how it can be used to aid the effective operations of internal control system. It concludes that the board has a greater responsibility of monitoring and reviewing the effectiveness of the internal control system for effective operations in the various banks.

Based on the findings above the following recommendati 
ons were suggested:

1. Overrid ing internal control system has been identified from the study as one of the factors that can result to ineffectiveness, distresses and failure in the system. Therefore satisfactory internal control and auditing system that cannot be overridden should be ensured by the board, regulatory bodies, directors and management.

2. Adequate checks and balances routine and spot checks, supervision and monitoring by the board and unscheduled visit by regulatory bodies should be encouraged to ensure compliance.

3. Furthermore, there should be a regular training for improvement on the part of the directors and management on corporate governance matters; ethical practices and CBN act on integrity and accountability.

4. There should be qualitative and quantitative evaluation of performance as regards productivity, effectiveness and accountability to aid the directors and management to be committed to their task with a crusading spirit and reward the faithful for effective performance.

5. There should be regular and effective feedback from the management and executives to the board on internal control matters.

6. The board should not relent on their oversight functions of effective monitoring and adequacy of the system of internal control in various banks.

\section{ACKNOWLEDGEMENTS}

SAP Productions wishes to acknowledge all the contributors for developing and maintaining this template.

\section{REFERENCES}

[1] Wikipedia, 2009, Online Available: (http://en.wikipedia.org/ corprate_governace)

[2] The free dictionary, 2010. Online Available: http://www. thefreedictionary.com/internal+control

[3] S.O. Alashi,. "Banking Crisis: Its Causes, Early Warning
Signals and Resolution" in Central Bank of Nigeria Conference Proceedings on Enhancing Financial Sector Soundness in Nigeria, CBN, Abuja, pp 126-153, 2002.

[4] A. A. Alawiye, "The banking reform agenda: the imperatives for corporate governance in a consolidated banking environment". The Nigerian Banker 15, no. 2, 11-17, 2006.

[5] L. Sanusi, Development in the banking system in Nigeria. Address by the Governor of the Central Bank of Nigeria in Saturday Tribune (2009). Online Available: http://www. tribune.com.ng

[6] Central Bank of Nigeria, (CBN). Code of Corporate Governance for Banks in Nigeria Post Consolidation. (Abuja: CBN Press, 1-20, 2006.

[7] O. A. Anya, "Corporate governance as an effective tool for combating financial and economic crimes". The Nigerian Banker 4 no. 3 (2003): 32-35.

[8] M. S. Nasser, Corporate govern ance in Islamic banks. Lubwic University Library, Munich, 2009. Online Available: $<$ http.// mpra.ub.uni-muechen.de/9255/>: 30-43.

[9] T.G. Arun, and J. D. Turner, Corporate governance of banking institutions in developing economies: the Indian experience. Paper presented in the conference on Finance and Development organized by IDPM, The University of Manchester, 2002.

[10] Organization of Economic Co-operation and Development OECD. Principles of Corporate Governance Paris: OECD), 2004.

[11] A. Akintola, Overview of corporate governance. A paper presented at the Continuing Professional Education (CPE I) Institute of Chartered Accountants of Nigeria (ICAN) held at Lagos, 1-19, 2010.

[12] O. Donovan, "A board culture of corporate governance". Corporate Governance International Journal, 6 (3): 12-18, 2003.

[13] B. Fakunle, Audit Companion Practice and Revision Kit, $2^{\text {nd }}$ Edition. Lagos: F. B. Ventures: 190-207, 2006.

[14] C. K. Unegbu, "Corporate governance in the Nigerian Banking Sector", A valedictory Speech of the outgoing president of the CIBN, Lagos, 2004.

[15] Institute of Chartered Accountants of Nigeria (ICAN), Financial Reporting and Audit Practice; Corporate Governance. Nigeria: VI Publishers, 345-348, 2006. 